\title{
Wait time as a driver of overall patient satisfaction in an ophthalmology clinic
}

\section{Michael McMullen \\ Peter A Netland}

Department of Ophthalmology, University of Virginia School of Medicine, Charlottesville, VA, USA
Correspondence: Peter A Netland Department of Ophthalmology, University of Virginia School of Medicine, PO Box 8007I5, Charlottesville, VA 22908-07I5, USA

$\mathrm{Tel}+\mathrm{I} 434982$ I086

Fax + I 4349245180

Email pnetland@virginia.edu

Correspondence: Michael McMullen Department of Ophthalmology, University of Virginia School of Medicine, PO Box 8007I5, Charlottesville, VA 22908-07I5, USA

Email mjmcmull2000@yahoo.com
This article was published in the following Dove Press journal:

Clinical Ophthalmology

19 August 2013

Number of times this article has been viewed

Purpose: The purpose of this study was to determine whether the actual time patients spend waiting is correlated with overall patient satisfaction scores.

Methods: This was a cross-sectional survey study conducted in an outpatient ophthalmology clinic. The actual time each patient waited to be called by the provider was recorded, and a survey was given at the end of the visit.

Results: There was a significant correlation between the time patients spent waiting and overall patient satisfaction scores $(P<0.001)$. Patients who were not completely satisfied waited twice as long as those who were completely satisfied $(P<0.001)$, regardless of whether patients received free care. Satisfaction with the amount of time spent waiting was the strongest driver of overall satisfaction score.

Conclusion: Minimizing the time patients spend waiting to see a provider can result in higher overall patient satisfaction scores, regardless of financial status.

Keywords: patient satisfaction, quality of care, wait time, ambulatory care

\section{Introduction}

In recent years, the public and health care administrators have placed increasing emphasis on quality of care. Patient satisfaction scores may be considered as a measure of care quality. The patients' perception of how long they waited has been associated with satisfaction scores. ${ }^{1,2}$ Some studies found that satisfaction with time spent waiting is a driver of overall satisfaction, ${ }^{1-4}$ and others did not. ${ }^{5,6}$ However, there is little information about whether the objective measurement of wait time is associated with patient satisfaction scores. In this study, our purpose was to determine if the actual time patients spend waiting to be seen by a physician is correlated with overall patient satisfaction in an outpatient ambulatory setting.

\section{Methods}

This was a cross-sectional study performed at the University of Virginia Health System outpatient eye clinic during March 2012. The study was approved by the Institutional Review Board, followed the recommendations of the Declaration of Helsinki, and conformed to the requirements of the United States Health Insurance Portability and Privacy Act. No patient-specific identifiers were recorded during the study.

A survey asked patients to rate on a scale of 1-7 (7 being the highest score) their satisfaction with various features of their visit. Questions were from the Press Ganey Associates, Inc (South Bend, IN, USA) ambulatory patient satisfaction survey instrument, which is the patient satisfaction survey used in the University of Virginia 
Health System. The Press Ganey survey has been validated, as described by the US Department of Health and Human Services Agency for Healthcare Research and Quality National Quality Measures Clearinghouse (NQMC, http:// www.qualitymeasures.ahrq.gov/content.aspx? $\mathrm{id}=34425$ ). Patients at least 18 years of age and who spoke adequate English to complete the survey were included. No patients who qualified for the study were excluded. Patients were not excluded based on the severity of their eye condition, education level, or reading ability. Both initial visits and follow-ups were included. Patients who gave a score of 7 were said to be completely satisfied, and those who gave a score less than 7 were said to be less than completely satisfied.

When a patient checked in at the front desk, the current time and pay rate (the number indicating into which category of financial assistance the patient fell) were recorded on the back of the survey, and the survey was placed in the patient's chart. None of the patients were interviewed or examined by technicians, and the physician was the first clinical staff member they encountered. When a physician called a patient into the exam room from the waiting room, the current time was recorded on the back of the survey. At the end of the appointment, the physician recorded the current time and handed the survey to the patient with instructions to complete the survey and return it to the front desk before leaving. The questionnaire was self-administered, although some patients may have asked for assistance from family members in reading the questions. No patient-specific identifiers were collected; thus, surveys were anonymous with the exception that they were handed to front-desk staff by the patient. Reading glasses were provided to patients whose eyes were dilated so that they could read the survey. The providers in the clinic were ophthalmology residents with faculty supervision present in the clinic. Eight of nine providers at the eye clinic participated in the study.

The time spent waiting was defined as the elapsed time between check-in time and the time when the patient was first called by the provider. Some patients were seen once by the provider, sent back to the waiting room prior to additional testing, returned to the waiting room after testing was complete, and then called a second time to complete the examination. In these cases, the additional time spent waiting after seeing the provider for the first time was not included in the time spent waiting variable. Only the time spent waiting between check-in and being called by the provider for the first time was considered.

Patients were assigned to a financial category (pay rate) that indicated their copay and coinsurance information.
The majority of patients fell into one of two categories: category 1, 100\% financial assistance (copay $\$ 3$; $0 \%$ coinsurance); or category 7 , no financial assistance (includes patients without insurance, with Medicare/ Medicaid, and those with third-party insurance). Pay rates falling between categories 1 and 7 represent different levels of financial assistance (coinsurance between 5\% and 80\%). For the analysis of cost of care results, cases where the pay rate fell between categories 1 and 7 were excluded (eleven cases). Patients falling into a category 1 pay rate represent those patients who truly receive free care, paying \$3 out of pocket with no coinsurance, regardless of the charges incurred by the visit. Those falling into a category 7 pay rate represent a heterogeneous group of patients receiving no discounted care. Out-of-pocket costs for patients in this category range from $100 \%$ of the visit charges, to only the copayment required by their insurer. In general, patients in category 7 incur more out-of-pocket expenses than those in category 1; however, the magnitude of this difference varies. The pay rate was recorded for each patient who was given a survey.

Sample size estimation was calculated for the study, indicating that a sample size of 37 in each group was needed in order to detect a 20-minute difference in the mean wait times, with an expected standard deviation of 30 minutes, a power of 0.80 , and an alpha of 0.05 . Spearman correlation coefficients and $P$-values were calculated. Welch's $t$-test, which does not assume equality of variance, was used to test for significance. $P$-values less than 0.05 were considered to be significant.

\section{Results}

Of 400 surveys distributed to patients, 104 were completed and returned, corresponding to a response rate of $26 \%$. Patient identifying information was not collected on the surveys, but the patients were sampled from a clinic population $(\mathrm{N}=57,343$ for the last fiscal year), with $27.1 \%$ of participants identifying as African-American, $59.0 \%$ as Caucasian, and $12.9 \%$ as another self-identified race. In the most recent fiscal year, the clinic population was $56.3 \%$ female (mean age 47.0 years) and $43.7 \%$ male (mean age 45.6 years). Wait times and patient satisfaction scores are shown in Table 1. The average wait time was $43 \pm 38$ minutes, with a range of 0 minutes to 184 minutes (coefficient of variation of $87 \%$ ). The average overall satisfaction score was $6.27 \pm 1.07$ (coefficient of variation of 17\%). The lowest average satisfaction score (5.49) was with time spent waiting. The highest 
Table I Wait time and satisfaction scores

\begin{tabular}{|c|c|c|c|c|c|}
\hline & $\mathbf{N}$ & Minimum & Maximum & Mean \pm SD & Variation \\
\hline Time spent waiting (minutes) & 104 & 0 & 184 & $43.0 \pm 37.7$ & $87 \%$ \\
\hline Overall satisfaction $(I-7)$ & 103 & 2 & 7 & $6.3 \pm 1.1$ & $17 \%$ \\
\hline Satisfaction with time spent waiting $(I-7)$ & 102 & I & 7 & $5.5 \pm 1.9$ & $34 \%$ \\
\hline Satisfaction with knowledge of doctor $(I-7)$ & 102 & 2 & 7 & $6.5 \pm 1.0$ & $16 \%$ \\
\hline Satisfaction with communication of doctor $(1-7)$ & 102 & 2 & 7 & $6.5 \pm 1.0$ & $16 \%$ \\
\hline Satisfaction with professionalism of doctor $(I-7)$ & 103 & 2 & 7 & $6.6 \pm 0.9$ & $13 \%$ \\
\hline Satisfaction with amount paid for visit (I-7) & 83 & 3 & 7 & $6.3 \pm 1.2$ & $19 \%$ \\
\hline Satisfaction with time spent with doctor $(I-7)$ & 103 & 2 & 7 & $6.5 \pm 1.0$ & $16 \%$ \\
\hline Satisfaction with privacy being respected $(I-7)$ & 102 & 2 & 7 & $6.6 \pm 0.9$ & $13 \%$ \\
\hline
\end{tabular}

Abbreviations: N, number; SD, standard deviation; Variation, coefficient of variation.

average score (6.63) was satisfaction with patient privacy being respected.

\section{Drivers of patient satisfaction}

Spearman correlation coefficients were calculated for all satisfaction questions. The correlation coefficients with overall satisfaction for each satisfaction question are shown in Figure 1. The variables with the three highest coefficients, in descending order, were satisfaction with time spent waiting $(P<0.001)$, knowledge of the doctor $(P<0.001)$, and time spent with the doctor $(P<0.001)$. The variables with the three smallest coefficients in ascending order are satisfaction with the amount paid for the visit $(P<0.001)$, professionalism of the doctor $(P<0.001)$, and respect of privacy $(P<0.001)$. Satisfaction scores for each question versus the overall satisfaction score are shown in Figure 2.

\section{Actual wait time versus overall patient satisfaction}

The average time spent waiting was calculated for each overall satisfaction score, as shown in Figure 3. There was a linear relationship between time spent waiting and overall satisfaction $\left(r^{2}=0.96\right)$, indicating that patients who had lower overall satisfaction waited longer $(P<0.001)$. Overall satisfaction was determined for patients who were completely satisfied (satisfaction score $=7$ ) and not completely satisfied (satisfaction score $<7$ ), and the average amount of time spent waiting was calculated for each group. Patients who were not completely satisfied waited twice as long as patients who were completely

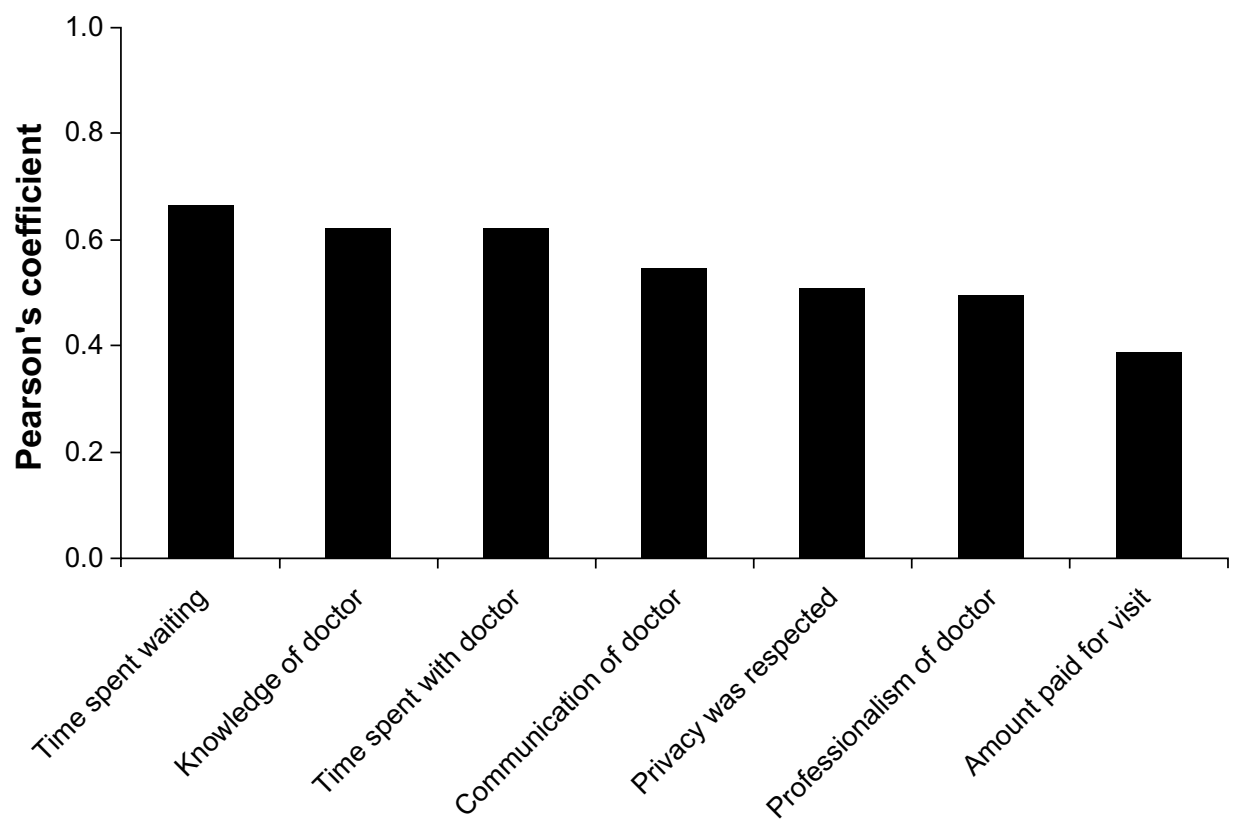

Figure I Correlation coefficients for drivers of overall patient satisfaction.

Note: $P$-values were less than 0.001 for all drivers (Spearman's correlation coefficients). 


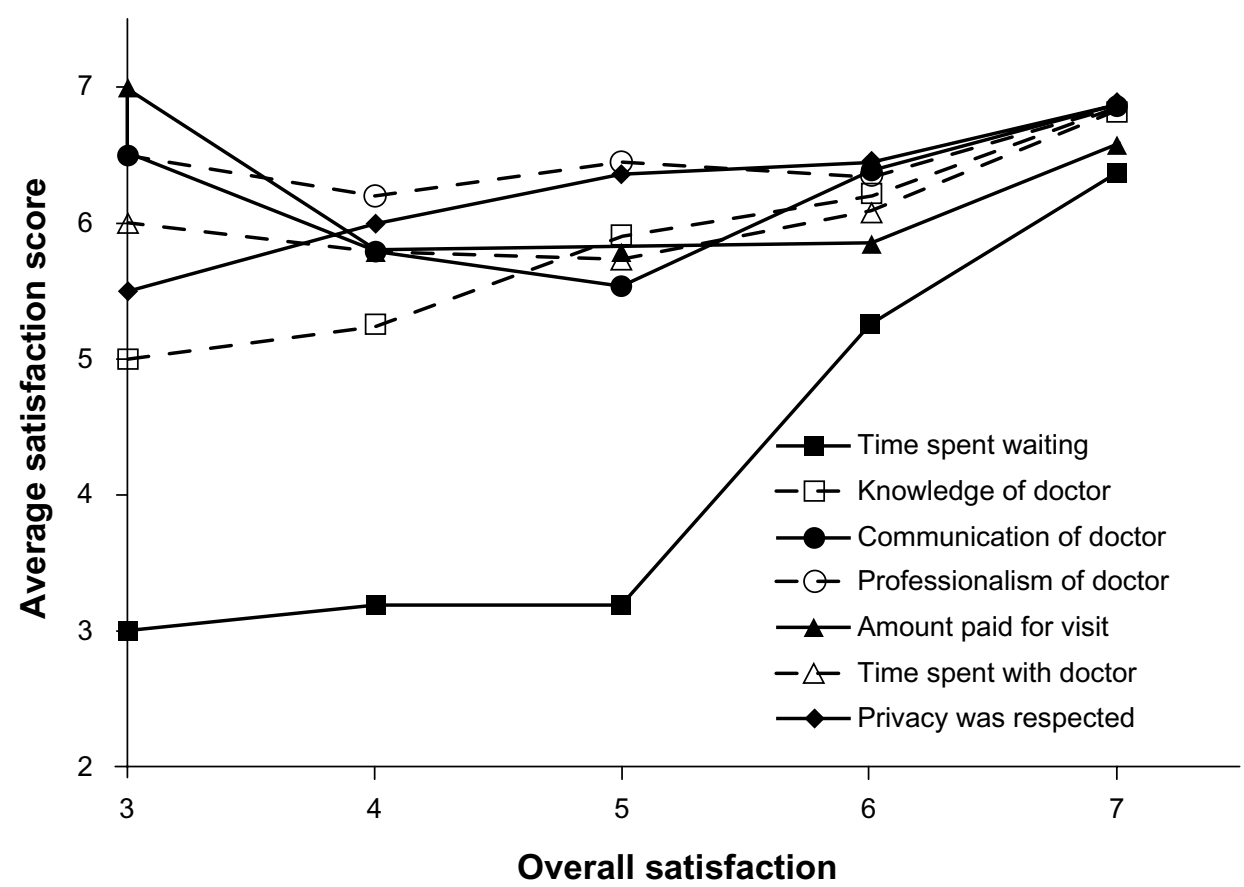

Figure 2 Average satisfaction for each driver and overall patient satisfaction. Note: Satisfaction was rated on a 7 -point scale, with 7 being the highest score.

satisfied ( $P<0.001$; Welch's $t$-test), with patients who were completely satisfied waiting an average of 30 minutes.

\section{Cost of care to patient versus time spent waiting and satisfaction}

The average overall satisfaction was calculated for patients in pay rate 7 (53 patients) and pay rate 1 (40 patients).
While patients in pay rate 1 were more satisfied with the amount paid for the visit $(P<0.001$; Welch's $t$-test $)$, there was no difference in overall satisfaction between the two groups ( $P=0.882$; Welch's $t$-test). The average time spent waiting by patients who were completely satisfied (satisfaction $=7$ ) and those who were less than completely satisfied (satisfaction $<7$ ) was compared by pay rate (Figure 4 ).

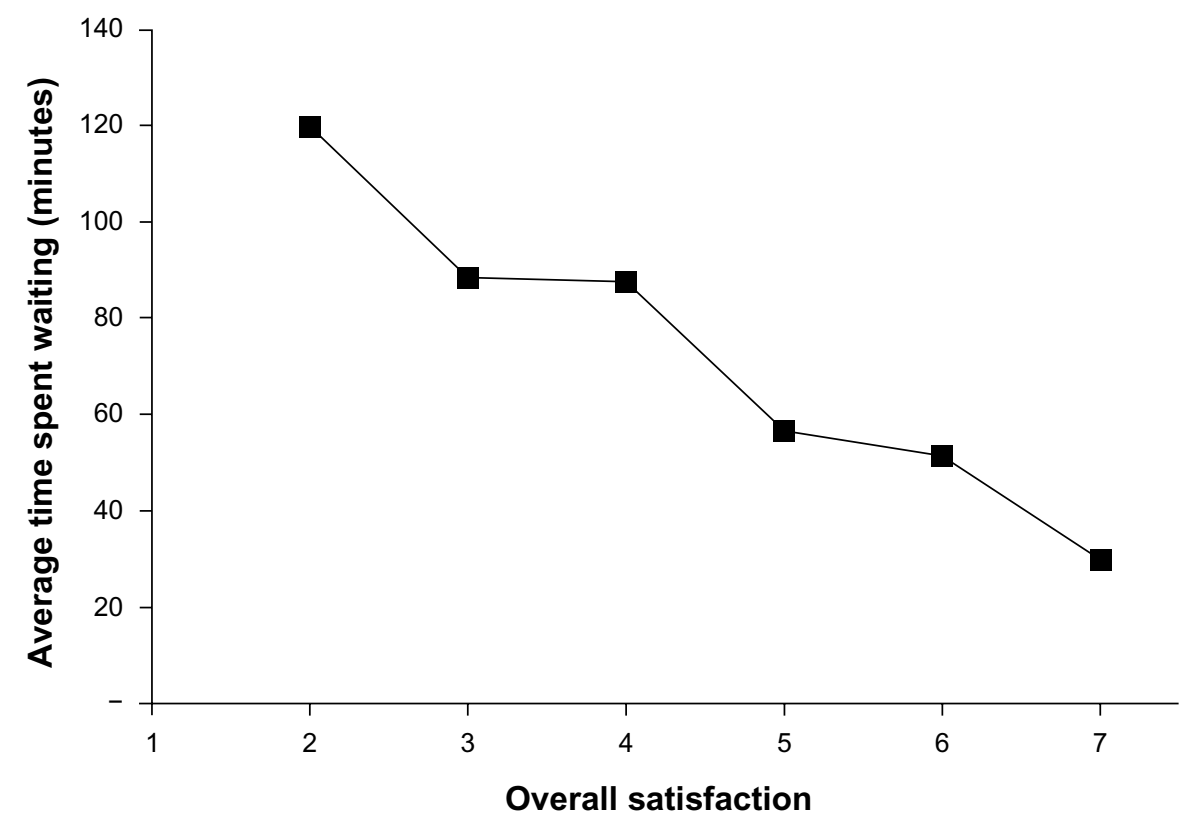

Figure 3 Average time spent waiting and overall patient satisfaction.

Note: Satisfaction was rated on a 7 -point scale, with 7 being the highest score. 


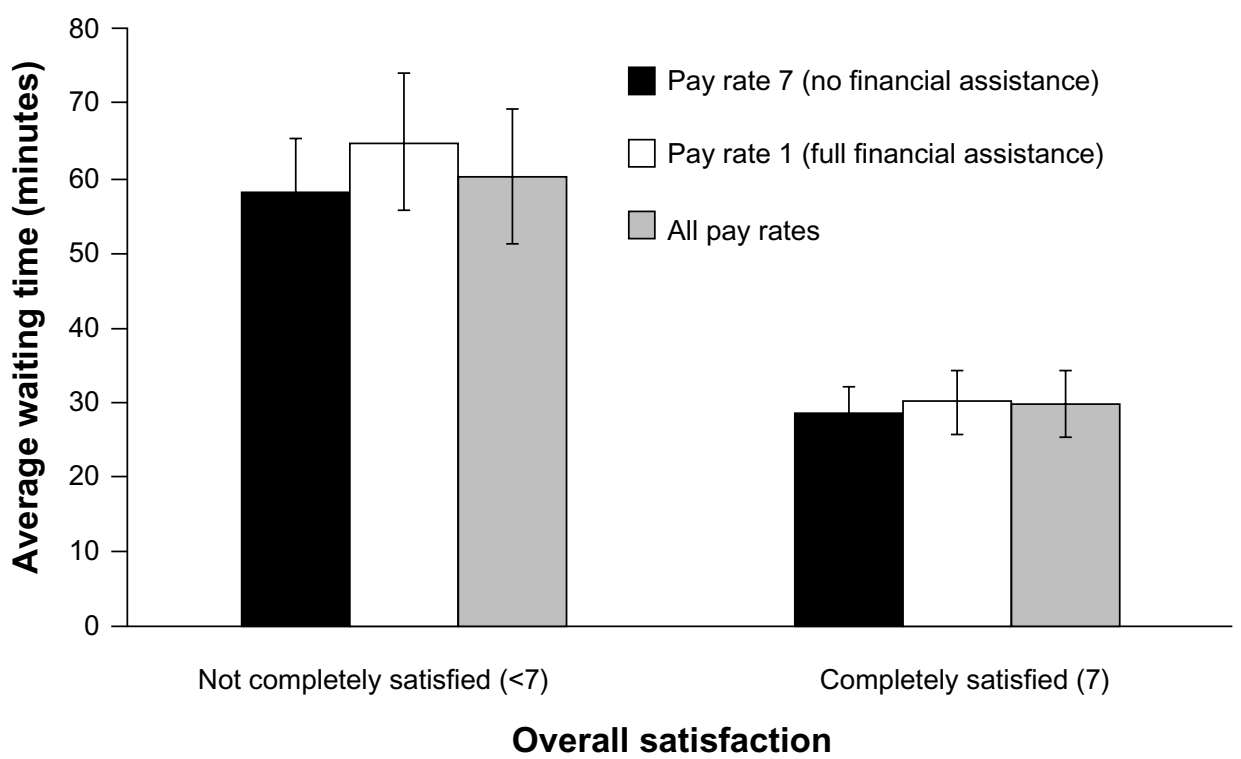

Figure 4 Average time spent waiting and overall satisfaction by pay rate.

Notes: $P$-values were $<0.00$ I for all pay rates, 0.004 for pay rate 7 , and 0.005 for pay rate I (Welch's $t$-test). Error bars indicate the standard error of the mean.

Those who were less than completely satisfied waited about twice as long as those who were completely satisfied regardless of pay-rate $(P<0.001$ all pay rates; $P=0.004$ pay rate 7 ; $P=0.005$ pay rate 1 ; Welch's $t$-test).

\section{Discussion}

Patient satisfaction is an outcome that can be measured in the ambulatory medical care setting. Overall patient satisfaction has been associated with patients' perceptions of wait times. ${ }^{1-4}$ This study, however, measured the actual time each patient spent waiting before being seen by the provider, providing objective information about this driver of patient satisfaction. In this study, wait time was associated with patient satisfaction, regardless of financial status.

There was a clear association between time spent waiting and overall patient satisfaction, with a linear relationship between these two variables. By fitting a linear regression line through the data points, the change in overall satisfaction by minute spent waiting was found to be one unit of overall satisfaction (on a scale of 1-7) for each 17-minute change in wait time, with a predicted overall satisfaction score of 7 (completely satisfied) for a wait time of 29.9 minutes.

We found that satisfaction with the time spent waiting was the driver most strongly correlated with overall satisfaction in the outpatient eye clinic. Patient satisfaction with the level of knowledge of the doctor, as well as with the amount of time spent with doctor, was also correlated with overall satisfaction. These findings suggest that clinics with highly variable and high wait times could most effectively increase overall patient satisfaction by employing methods to increase patient satisfaction with wait time, which has been previously shown. ${ }^{1-4}$

The fact that satisfaction with time spent with the physician is also strongly associated with overall satisfaction suggests that strategies employed to decrease clinic wait times should not do so at the expense of face-to face time with the patient. However, previous literature has not clearly identified an association between actual time spent with physician and patient satisfaction. ${ }^{7}$ This study did not determine if certain face-to-face interactions between the physician and patient are more closely linked to overall satisfaction than others, such as checking vision or counseling. While the actual amount of time spent face-to-face with a physician may be correlated with patient satisfaction, our study found no significant association of patient satisfaction with the time before check-out minus the wait time.

The cost of care was not found to change the association between wait time and patient satisfaction. Patients who received free care were just as dissatisfied with high wait times as those without any financial assistance. While the out-of-pocket cost to patients not receiving free care varies a great deal, lower levels of satisfaction with the amount paid for the visit in the group not receiving free care indicates that the difference in out-of-pocket costs between the two groups is significant. This study demonstrates that patient satisfaction is higher in patients who experience less wait times, even in an outpatient eye clinic, with a high percentage of patients receiving free care. 
Limitations of this study include the bias inherent in survey studies. Only patients in one institution's outpatient eye clinic were surveyed, and the results may not generalize to other specialties or ophthalmology clinics. This is a relatively small study with just over 100 patients surveyed, and the response rate was low. While providers were asked to distribute surveys to all patients that met the inclusion criteria, this process was not monitored, and selection bias may have been introduced. All providers in this study were resident physicians in a comprehensive ophthalmology clinic. It is not known whether the results would differ in a faculty or subspecialty clinic, which would be a potential area for further study.

This study shows that patient satisfaction is strongly associated with actual clinic wait times, and that to maximize overall satisfaction, actual wait times should be less than approximately 30 minutes. While wait time appeared to be a strong driver of patient satisfaction, it is possible that other aspects of the visit may have been important, but were not measured. The numeric relationship between wait time and patient satisfaction can be used to predict patient satisfaction, which can be helpful with clinic scheduling. This study provides evidence that the actual time patients spend waiting to be seen can strongly influence patient satisfaction scores.

\section{Acknowledgments}

Dr Netland receives research support from Alcon, Solx, and New World Medical. Results from this study were presented in part at the Virginia Society of Eye Physicians and Surgeons, Arlington, VA, USA, June 22-23, 2012.

\section{Disclosure}

The authors report no conflicts of interest in this work. The authors have no proprietary interest in this material.

\section{References}

1. Billing K, Newland H, Selva D. Improving patient satisfaction through information provision. Clin Experiment Ophthalmol. 2007;35(5): 439-447.

2. Anderson RT, Camacho FT, Balkrishnan R. Willing to wait?: the influence of patient wait time on satisfaction with primary care. BMC Health Serv Res. 2007;7:31.

3. [No authors listed]. Lean-driven improvements slash wait times, drive up patient satisfaction scores. ED Manag. 2012;24(7):79-81.

4. Zopf D, Joseph AW, Thorne MC. Patient and family satisfaction in a pediatric otolaryngology clinic. Int J Ped Otorhinolaryngol. 2012;76(9): 1339-1342.

5. Trentman TL, Cornidez EG, Wilshusen LL, et al. Patient satisfaction in an academic chronic pain clinic. Pain Pract. 2012;13(5):372-379.

6. Dang BN, Westbrook RA, Rodriguez-Barradas MC, Giordano TP. Identifying drivers of overall satisfaction in patients receiving HIV primary care: a cross-sectional study. PLoS One. 2012;7(8):e42980.

7. Rothberg MB, Steele JR, Wheeler J, Arora A, Priya A, Lindenauer PK. The relationship between time spent communicating and communication outcomes on a hospital medicine service. J Gen Int Med. 2012;27(2): 185-189.
Clinical Ophthalmology

\section{Publish your work in this journal}

Clinical Ophthalmology is an international, peer-reviewed journal covering all subspecialties within ophthalmology. Key topics include: Optometry; Visual science; Pharmacology and drug therapy in eye diseases; Basic Sciences; Primary and Secondary eye care; Patient Safety and Quality of Care Improvements. This journal is indexed on Submit your manuscript here: http://www.dovepress.com/clinical-ophthalmology-journal

\section{Dovepress}

PubMed Central and CAS, and is the official journal of The Society of Clinical Ophthalmology (SCO). The manuscript management system is completely online and includes a very quick and fair peer-review system, which is all easy to use. Visit http://www.dovepress.com/ testimonials.php to read real quotes from published authors. 